\title{
Estudio cualitativo de la metáfora como vehículo de encuadre en los textos noticiosos sobre los atentados del 11-m (El País, The Guardian e Izvestia)
}

\section{The qualifying study of metaphor as a vehicle of frame in the news texts about 11-m terrorist attacks (El País, The Guardian and Izvestia)}

\author{
Mukhortikova, T. ${ }^{1}$
}

Recibido: 09-11-2017 - Aceptado: 14-06-2018

DOI: https://doi.org/10.26441/RC17.2-2018-A9

RESUMEN: El presente artículo aborda el estudio de la metáfora como una estrategia de la interpretación de los atentados terroristas perpetrados en Madrid el 11 de marzo de 2004 en tres diarios editados en distintas lenguas y en diferentes países. El texto ofrece la mirada pluridisciplinar a la metáfora, apoyándose en la interpretación de dicha figura como una de las formas lingüísticas de la interpretación de la realidad en un texto periodístico y la llamada teoría de encuadre (framing).

Palabras clave: metáfora; encuadre; lenguaje periodístico; metáfora periodística.

ABSTRACT: This article includes the study of metaphor as a strategy for interpreting the terrorist attacks perpetrated in Madrid on March 11, 2004 in three newspapers published in different languages in different countries. The text offers a multidisciplinary view to the metaphor, based on the interpretation of this figure as one of the linguistic forms of the interpretation of reality in a journalistic text and the so-called framing theory.

Keywords: metaphor; frame; media language; journalistic metaphor.

\section{Introducción}

Una de las tendencias destacadas en la ciencia actual es la colaboración de diversos campos, la aparición de investigaciones y temarios relativos al mismo momento a dos o más ámbitos científicos. Un ejemplo ilustrativo de este fenómeno sería un estudio de la metáfora en los textos periodísticos en relación con la llamada teoría de encuadre, un méto- do apropiado para el análisis de los textos noticiosos. Consideramos la importancia de combinar este enfoque con un acercamiento más detallado, micro, a través de otro mecanismo que resulta muy productivo a la hora de presentar fenómenos novedosos, como es el caso de la metáfora, que por su capacidad cognoscitiva constituye un elemento básico en la percepción del mundo. A

1 Tatiana Mukhortikova es licenciada en periodismo por la Universidad Estatal de Moscú "M.V. Lomonosov" (Rusia) y Máster en Investigación en Lenguas y Literaturas. Cursa el Doctorado en Lenguas, Literaturas, Culturas y sus Aplicaciones en la Universidad de Valencia. tamuk@alumni.uv.es, http://orcid.org/0000-0002-6742-1219 
través de la metáfora se concreta y detalla la interpretación de los acontecimientos, de manera que, en combinación con el framing, ambas permiten tener una visión más rica de la cobertura de un objeto informativo en los medios de comunicación con el objetivo de analizar encuadres y metáforas de la cobertura informativa de dos los atentados del 11-M.

\section{El frame y la metáfora en el texto noticioso}

Los estudios prácticos del periodismo permiten relacionar el texto con las circunstancias que lo rodean, analizarlo como un resultado del proceso de la producción de una noticia, en el que participan la interpretación personal del periodista, los valores informativos, etc. El método apropiado para este tipo de análisis es el framing (teoría de encuadre), pues a pesar de la supuesta ausencia del componente valorativo en los textos informativos resulta imposible transmitir noticias sin dar preferencia a unos aspectos sobre otros, a unos acontecimientos sobre los demás (Sádaba, 2001; 2008). Como respuesta a la mirada objetivista, los estudios de los textos noticiosos en el marco de framing intentan unir el análisis de los elementos textuales con el contexto, los valores e interpretaciones detrás del texto (Pan \& Kosicki, 1993). El frame (encuadre) como una idea central del texto periodístico que desenmascara el contenido del mensaje informativo central (Gamson \& Modigliani, 1989, p. 3) permite destacar las "fronteras" establecidas, observar qué aspectos de la reali- dad se hicieron más visibles en el texto y qué punto de vista particular forman (Entman, 1993, p. 52).

Los frames o encuadres, en opinión de Entman, al mismo momento determinan el problema, destacan sus causas y proponen posibles soluciones (1993, p. 52). El autor establece dos niveles del framing: los principios mentales del proceso comunicativo y las características del texto periodístico (1991, p. 7). En el ejemplo del encuadre "guerra fría" (1993) destaca cuatro componentes del frame que actúan en el acto comunicativo: el comunicante, que comunica el encuadre según sus creencias y experiencias; el texto, que transmite determinadas ideas, el receptor que descifra estas ideas; y la cultura que regula este proceso. Así, los emisores deciden qué comunicar y qué no comunicar por influencia de los encuadres culturales (Entman, 1993). Gamson y Lash destacan tres niveles de encuadre: mecanismos manifiestos del framing, mecanismos de razonamiento y el fenómeno cultural implícito (Gamson \& Lash, 1983).

Los encuadres textuales se manifiestan en la presencia o ausencia de determinadas palabras, las imágenes estereotípicas, o, entre otras, las fuentes de información (Entman, 1993, pp. 5253 ), e indican al receptor una conclusión determinada que influye en una interpretación particular del objeto (Entman, 1991; 1993). La cultura supone el uso de unos encuadres típicos de la misma (Entman, 1993; Van Gorp, 2007). Como indica Van Gorp, los frames del texto noticioso deben analizarse 
teniendo en cuenta la especificidad de la cultura en la que se formaron, puesto que manejan por modo de la memoria colectiva de la sociedad, a la que corresponden tanto el periodista como los lectores (2007, p. 73). Los artículos abarcan fragmentos de información que ejecutan por medio del reparto, la repetición o por analogía con símbolos culturalmente conocidos (Entman, 1993, p. 53). Entman distingue entre los frames noticiosos que actúan en el nivel textual, como palabras clave, símbolos, metáforas, conceptos y acompañamiento visual (1991, p. 7). Gamson y Lash (1983, p. 410) y Van Gorp (2007, p. 64), destacando también la metáfora y la imagen visual, añaden a la lista más elementos, como por ejemplo, frases de enganche, representaciones, descripciones, argumentos o la selección de palabras. Entman expone cómo el uso de diversos frames forma diferentes interpretaciones de la misma situación (1991). Scheufele interpreta el encuadre como un modelo interactivo de la construcción de la realidad adaptado a la teoría de los efectos de los medios (1999, pp. 105-106). Los estudios empíricos muestran que el encuadre, la presentación de un objeto informativo en los medios sistemáticamente afectan a la percepción de este por parte de los lectores (1999, p. 105). La teoría de encuadre aplicada al estudio de la cobertura informativa de los atentados terroristas permite destacar los aspectos subrayados, las ideas centrales que pretende transmitir un medio de comunicación, y que conforman un determinado punto de vista sobre el objeto informativo.
En uno de los trabajos más recientes, Entman especifica que los encuadres, tras indicar la interpretación determinada de los hechos, pueden definir los efectos y las consecuencias de la situación problemática, destacar las causas, valorar e indicar las posibles soluciones (2003, p. 417). Según Lakoff, el frame es una idea, un concepto amplio, un modo dominante para la comprensión de un fenómeno en una época y en una sociedad. El autor interpreta el marco como un tipo de estructura cognitiva que organiza nuestra percepción del mundo, e influye en nuestra forma de actuar. De ahí, el cambio social se refleja en un cambio en el marco (2007, p. 4). Como ejemplo de este cambio, Lakoff pone los atentados del 11 de septiembre 2001. Este atentado provocó la modificación de la percepción del mundo por los ciudadanos norteamericanos. El ataque contra las torres se interpretó, por analogía, como el ataque a la sociedad y sus miembros. Los edificios fueron entendidos como una metáfora del hombre (2007, p. 46). Los republicanos y los demócratas reaccionaron por encuadres diferentes, pero todos cambiaron las líneas de sus discursos. El marco común que generaron los acontecimientos del 11 de septiembre es de "guerra". Analizando el tratamiento informativo de los atentados del 11-S, distintos autores concluyeron que el encuadre "global" que está detrás de los discursos periodísticos es la "guerra contra el terrorismo" (Lakoff, 2007: 50-51; Reese \& Lewis, 2009: 88).

En cuanto a la definición práctica de los encuadres, Cappella y Jamieson, 
hablando sobre los textos periodísticos dedicados a las elecciones políticas, diferencian entre encuadres estratégicos ("strategic frames") que recuerdan al auditorio el interés de vencer las elecciones, y encuadres temáticos ("issue frames"), que se refieren a las cuestiones concretas de campaña (1996, pp. 81-82).

Por último, Portilla (2012), basándose en el análisis de los frames en la prensa mexicana sobre el narcotráfico, propone un esquema metodológico que resume las ideas anteriores y ofrece una aproximación que nos parece adecuada como base para la definición de los encuadres. Esta propuesta resulta interesante también porque el autor, en la práctica, considera la metáfora como una de las estrategias semánticas del encuadre (2012, p. 63). En la primera fase del análisis, Portilla propone destacar los encuadres a través de sus funciones en el texto, lo que remite a Entman (1991; 1993; 2003): definición del problema, interpretación de las causas, calificación y recomendaciones del tratamiento (2012, p. 62). En la segunda fase plantea definir los encuadres genéricos, que el autor (basándose en los textos periodísticos sobre el narcotráfico y siguiendo la línea de Semetko \& Valkenburg (2000) separa en cuatro categorías: de conflicto, de responsabilidad, de interés humano y de consecuencias económicas (2012, p. 63). En esta etapa, el autor analiza las metáforas conceptuales como un tipo dentro de la estrategia de encuadre. La tercera fase supone el estudio del uso metafórico del término "guerra" en los textos dedi- cados al narcotráfico (2012, p. 64). En otras palabras, el autor relaciona las metáforas de la esfera semántica "guerra" con el encuadre "la guerra contra el narcotráfico".

\section{Metodología y corpus}

En el ejemplo de la cobertura informativa de los ataques terroristas perpetrados en Madrid el 11 de marzo de 2004 proponemos realizar el análisis de la metáfora como un elemento lingüístico que transmite el frame del texto informativo. De acuerdo con las afirmaciones puestas de manifiesto por los autores citados (Entman, 1991, 1993; Lakoff, 2007; Van Gorp, 2007), en el proceso de la creación de los encuadres influyen diversos factores contextuales. Entre elementos que contribuyen a la aparición de los frames se sitúa la especificidad de un medio de comunicación (su desarrollo histórico, orientación política, el sector y la posición que ocupa dentro del sistema de la prensa nacional, etc.). Estos componentes constituyen el marco cultural, cuyo análisis predomina en los estudios recientes sobre el periodismo (Reyna García, 2017, p. 4).

Por tanto, la selección de los periódicos para el análisis responde a sus similitudes tanto por la difusión como por la autoridad con la que cuentan en sus países respectivos. Son diarios, que en el año 2004 pertenecen a la prensa de calidad, tienen una trayectoria histórica importante; poseen altos índices de venta y de lectura diaria en el momento estudiado.

El periódico The Guardian, comienza su historia en el año 1821, cuando el 
comerciante J. E. Taylor fundó The Manchester Guardian (Gómez Mompart \& Marín Otto, 1999, p. 60). La época de mayor crecimiento y evolución del diario vincula al nombre de C. P. Scott, que llegó al puesto de director del periódico en el año 1871 y siguió en él durante 57 años (desde 1907, el propietario del diario). En su política editorial, declaró los principios de la independencia del diario de los intereses de cualquier grupo (Cole \& Harcup, 2010, pp. 76-77). En 1936 el hijo de C. P. Scott, J. R. Scott, estableció el Scott Trust como un negocio familiar. Este principio de la propiedad del periódico de alguna manera asegura la independencia mayor de sus contenidos y protege la continuidad del nivel alto de experiencia y conocimiento del sector (2010, p. 77).

En 2004 The Guardian se sitúa entre cinco periódicos de calidad a nivel de difusión nacional, uno de los periódicos de autoridad internacional y responde a la tendencia liberal actuando como un medio independiente para el debate sobre cuestiones significativas en las esferas política y social (Schulze, 2004, pp. 216-217).

Izvestia fundado en 1917, como el periódico oficial del órgano representante de los trabajadores y los soldados, tiene una larga historia si se compara con otros periódicos soviéticos y rusos. Durante la época soviética actuó como el periódico oficial de los órganos estatales. El período más transcendental en la historia de Izvestia se vincula al nombre de A.I. Adzhubéj, que fue el director del diario durante cinco años (19591964). Vólkova (Волкова) indica que sobre la base del periódico del partido comunista, Adzhubéj creó un diario político-social que se convirtió en uno de los símbolos del "Deshielo de Jrushchov" (el período del gobierno de Nikita Jrushchov en la Unión Soviética caracterizado por la suavidad de la represión política y la censura) y adquirió popularidad entre la población (2009, pp. 3-26).

Los cambios en el sistema de la prensa rusa de los años 90 afectaron también al diario Izvestia. La necesidad de modernizar el lenguaje, las características de la comunicación o los propios géneros periodísticos transformaron la estructura del periódico. Cuando hace referencia a las tendencias existentes en la prensa a principio de los años 2000, Ovsepján (Овсепян) define Izvestia como un periódico político independiente de organizaciones y orientaciones concretas (2005, p. 112). En marzo de 2004, el diario estaba en la propiedad de la compañía Prof-Media. A finales de 2004, el periódico fue destacado por el Servicio Nacional de Imprenta (Национальная тиражная служба) como el diario con el mayor índice de imprenta en el sector de la prensa nacional de calidad (Servicio Nacional de Imprenta, 2 de diciembre de 2004).

Aunque El País tiene una historia menos extensa poseía una autoridad similar en su territorio en el momento estudiado. Propiedad del Grupo PRISA, accionista mayoritario del periódico en el momento de los atentados de Madrid, el rotativo fue fundado en 1976 por el hijo del filósofo José Ortega y Gasset, José Ortega Spottorno, Jesús de 
Polanco, Juan Luis Cebrián, Darío Valcárcel y Carlos Mendo. El País se convirtió en el diario de mayor autoridad y más popular de la España postfranquista, y conquistó especialmente a un sector de lectores de la izquierda (Seoane \& Saiz, 2007, p. 298; Seoane \& Sueiro, 2004, pp.17-18). En el año 2004, es el diario más difundido en España, según los datos de la Oficina de Justificación de la Difusión (OJD) (El País, 20 de febrero de 2005).

El estudio práctico de encuadres y metáforas escogidas consta de dos fases. En primer lugar, se trata de la definición de los encuadres de cada uno de los tres diarios; la segunda fase remite al análisis estructural de las metáforas destacadas.

Hemos destacado los encuadres de cada uno de los periódicos partiendo de las propuestas señaladas arriba, especialmente las ideas de Entman (1991; 1993), y Portilla (2012) sobre la base de los textos. Teniendo en cuenta la especificidad del corpus hemos decidido separarlos por categorías, según el aspecto del evento que describen: la descripción del evento y la reacción generada. En primer lugar, se trata de los encuadres que se pueden definir como descriptivos, ya que se refieren a diversos aspectos del atentado, describen el hecho en sí mismo. Este tipo de encuadres se enfoca en las imágenes de catástrofe, guerra, etc. y se opera por las metáforas conceptuales. Los encuadres de esta categoría describen los lugares del atentado, las historias humanas detrás de lo ocurrido, los sentimientos que han experimentado las víctimas. En el mismo bloque se refiere a la cobertura informativa de los ataques en los medios del país atacado, y la política informativa del Gobierno del país. Se hacen referencias a la responsabilidad de estos en el caso de cometer errores en la información ofrecida durante el ataque o en los días posteriores. Otra categoría la hemos denominado encuadres de consecuencias y reacciones. Los encuadres de esta categoría remiten a la reacción emocional de los ciudadanos y a la reacción oficial de los políticos a nivel nacional e internacional y la influencia en la política interior o exterior del país que han provocado.

El análisis empírico de las metáforas se basa en la propuesta de Teruel (1997) sobre el estudio cognitivo interpretativo de la metáfora periodística que parte de la teoría de Lakoff y Johnson (1995). En la estructura de la expresión metafórica la autora destaca tres componentes: el foco, o palabra que funciona como el núcleo de la expresión metafórica. Por ejemplo, una tormenta bancaria; el marco, que es aquella parte de la expresión que subraya el foco y completa el significado. La característica de las metáforas periodísticas consiste en que el marco no siempre se presenta verbalmente en la expresión. A veces, se expresa por medio de las ilustraciones $\mathrm{u}$ otros elementos adicionales. Como destaca Teruel, en el caso de los titulares, puede contenerse en el texto posterior, en el artículo (1997, pp. 236-237). Este hecho se puede explicar también por la estructura del texto periodístico en forma de pirámide invertida. Por último, el tema (el conjunto de cuestiones que se 
tratan en un determinado artículo periodístico) (1997, pp.235-240).

En la parte interpretativa del análisis, siguiendo a Teruel, remitimos a los campos ontológicos para destacar la esfera de traslación semántica de la metáfora (1997, p. 249). En las páginas siguientes proponemos utilizar el término esfera semántica o campo semántico o esfera de significado, para referirse al campo de donde procede la traslación semántica del evento/situación/persona correspondiente. $\mathrm{Al}$ realizar un análisis de metáforas de los titulares de la prensa la autora propone una serie de las esferas semánticas: Monstruos e imaginario (metáforas de pesadillas, sueños, horrores, etc.); Tiempo (fenómenos atmosféricos e intervalos temporales); Geo (expresiones relativas a la tierra); sentidos (los sentidos y las costumbres de una determinada cultura, es decir, gusto, olfato, comida, tacto, vista y oído); Poder y soberanía; Hombre (con subcampos salud, ropa y estética, anatomía, pasiones y sentimientos, etc.); Espacio (frases relativas al movimiento en el espacio); Justicia; Casa; Educación; Calor (expresiones que remiten a la temperatura de cuerpo o substancia); Divinidad (todas las frases relativas a religiones y dioses); Muerte; Juego (incluyendo el mundo del espectáculo); Guerra; Deporte; Música; Agua; Aire; Industria (incluyendo máquinas y manufactura); Dinero; Mar (actividades o fenómenos naturales que remiten al mar); Animales (1997, pp. 250-269).

El corpus presenta frames y metáforas empleados en los textos informativos de tres periódicos procedentes de tres países con culturas periodísticas distintas y editados en idiomas diversas: $E l$ País (España), The Guardian (Reino Unido) e Izvestia (Rusia), sobre los atentados perpetrados en Madrid el 11 de marzo del 2004, que ha sido el ataque más grave en la historia de España.

Los límites temporales de la selección del corpus responden a la atención en el tratamiento por parte de los medios, por lo que se han acotado quince días de seguimiento, a partir del día posterior a los atentados. En el caso de El País se han seleccionado 34 textos publicados del 12 al 25 de marzo 2004, en el caso de The Guardian -12 artículos del 12 al 16 de marzo 2004, y en el caso de Izvestia- 6 textos del 12 al 20 de marzo 2004. Destacamos en los textos una serie de encuadres y metáforas que los transmiten y que exponemos a continuación.

\section{Encuadres y metáforas de El País 4.1. Encuadres descriptivos \\ El escenario del drama y la tragedia}

Las metáforas que presentan los ataques en Madrid como un espectáculo se pueden diferenciar entre las que remiten a la idea de espectáculo en general y contienen este sustantivo, las que se refieren a la construcción teatral, como es el escenario, las metáforas de "escena", como parte de la representación de la obra teatral, la "trama" o la "secuencia”, y dos grupos de expresiones que remiten a la tragedia y el drama a la hora de calificar los atentados. Las metáforas pertenecen a la esfera semántica "Juego (mundo del espectáculo)". 
El ejemplo 1 narra la experiencia que tuvo un médico traumatólogo al llegar en uno de los primeros equipos a la zona de los atentados. La situación que encontró en la estación de Atocha se califica con la expresión "espectáculo terrible”. El "espectáculo" es el foco de la metáfora, transmite la idea del alcance de la destrucción y de la imposibilidad de comprender lo ocurrido.

Ej. 1. El espectáculo que vio fue terrible (...) (EP, 12.03.2004).

Dos metáforas seleccionadas remiten al término "escena" como parte del espectáculo y transmiten algunas de las imágenes de la zona afectada por las explosiones. El ejemplo 2 llama la atención por el uso de la alusión cultural o literaria: la metáfora remite a la obra de Dante Alighieri, La Divina comedia. El sustantivo "escena" se intensifica por el adjetivo "dantesca", remitiendo al estilo y los temas de la escritura de este autor. La obra de Dante contiene numerosas imágenes de horror, violencia y crueldad que generan la reacción emocional. A su vez, el ejemplo 3 remite al ambiente emocional en el lugar de la explosión y presenta las imágenes percibidas como "escenas" capaces de generar sentimientos. La "escena” conecta las imágenes aparecidas con los sentimientos que despiertan en los "espectadores": dolor, angustia e impotencia.

Ej. 2. (...) en otro tren con el mismo destino (...) explotaron cuatro bombas (...) que causaron 64 muertos y escenas dantescas en la vía (...) (EP, 12.03.2004).

Ej. 3. Escenas de dolor, angustia y mucha impotencia se vivieron du- rante las horas siguientes (EP, 12.03.2004).

Un grupo de metáforas remite al término "escenario", un elemento esencial del edificio o la construcción del teatro, donde tiene lugar la representación del espectáculo. El ejemplo 4 presenta el lugar físico de la explosión producida como el "escenario". La asociación similar presenta el ejemplo 5 de uno de los reportajes del día 13 de marzo, que describe el ambiente en la estación de Atocha. La estación se asocia con el escenario del teatro en el mismo sentido que la expresión anterior, mientras el atentado se califica como una acción antihumana y antisocial, lo que se concreta en el sustantivo "crimen".

Ej. 4. Una señora pregunta en el escenario del atentado: "¿Pero qué quiere esa gente de nosotros?” (EP, 12.03.2004).

Ej. 5. Así era el escenario del crimen un día después (EP, 13.03.2004).

El ejemplo 6 describe a los terroristas como los personajes de la obra literaria y el atentado como esta obra, remitiendo a la esfera. El sustantivo "trama" se usa aquí para indicar la complejidad, y, en particular, señalar que uno de los aspectos de la misma fue una ciudad alejada del lugar de los atentados. A la trama le atribuye la capacidad de guiar a alguien al sitio correspondiente.

Ej. 6. La trama de los atentados de Madrid pasa por la ciudad del

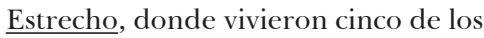
marroquíes detenidos en España (EP, 23.03.2004).

Hemos seleccionado tres ejemplos ilustrativos del uso metafórico de los 
sustantivos "drama" y "dramatismo". El ejemplo 7 trata de describir el relato de los heridos en el atentado, sus historias personales relacionadas con los acontecimientos. El atentado se interpreta como un "drama" y las víctimas, los heridos, los testigos son los personajes participantes en él. Sus historias presentan una parte del drama común, cada una de ellas es un "capítulo del drama”. La segunda expresión (ejemplo 8) se refiere al drama como la historia de una familia. Una de las heridas, la mujer se quedó con un niño pequeño porque su marido murió en el atentado. El foco semántico del ejemplo 9 es el sustantivo "dramatismo", que se emplea aquí con el sentido de "dramático". La metáfora transmite la percepción de los atentados por parte de participantes, como son las víctimas, los vecinos de la zona del atentado, etc.

Ej. 7. Cada cual contaba su historia,

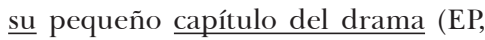
13.03.2004).

Ej. 8. Drama de una pareja ecuatoriana (EP, 12.03.2004).

Ej. 9. Fuera del cordón policial se vivieron los momentos de gran dramatismo (EP, 12.03.2004).

El último grupo de metáforas presenta las explosiones de trenes de Madrid como una tragedia no prevista con unas consecuencias dramáticas. El rasgo característico del uso de estas metáforas es que se emplean en diversas "variedades" temáticas en los textos sobre los atentados, desde los reportajes de las estaciones atacadas hasta las historias sobre las víctimas y sus familiares. Los ejemplos ilustrativos muestran también la intensidad del uso de este término: se emplea desde el primer número después de los ataques hasta unos materiales publicados casi dos semanas después. La causa de este fenómeno cabe buscarla en las reglas del género de la tragedia, en sus raíces en la Antigüedad clásica. La tragedia presenta la idea de la fatalidad del destino humano. El acto del terrorismo, a su vez, es algo que no podemos prever, algo que le atribuye el valor fatal.

Dos metáforas recogidas de los textos de análisis (ejemplos 10 y 11) remiten a la tragedia como algo que se debe "afrontar" o que puede tener una "magnitud". Es decir, la interpretan de una forma metafórica como un objeto físico que puede tener dimensiones en una escala de posibilidades y obliga a reaccionar frente a ello. En el primer caso (ejemplo 10) se presenta como "magnitud" la gran cantidad de las víctimas y el carácter de los atentados. En el ejemplo 11 la "tragedia" muestra la gravedad de la situación, a que se enfrentaron las personas. En este caso "tragedia" se usa como un sinónimo del peligro. El ejemplo 12 presenta los trenes como lugar de la tragedia, el escenario donde se desarrolló el 'espectáculo'. En el mismo tiempo, el tren como tipo del transporte tiene un valor simbólico: la tragedia ha llegado en el tren, por esta vía la tragedia entró en Madrid. El ejemplo 13 denomina a los médicos, los servicios de rescate como "héroes". El término héroe contiene dos significados: el hombre que realiza algo heroico y el personaje de la obra literaria, la tragedia. Intensifica el primer sentido el 
adjetivo "anónimo", ya que sus nombres, a pesar del trabajo que realizan, raramente se hace público. El ejemplo 14 contiene el sustantivo "desfile", el carácter de este desfile se define por el adjetivo "trágico". La búsqueda de sus parientes por parte de los familiares y su identificación se asemeja con un "desfile" también por la cantidad de personas que acude para proceder a la identificación. El ejemplo 15 describe la cronología de los atentados. Las explosiones se califican como una "secuencia mortal", donde el sustantivo "secuencia" es el foco de la expresión metafórica y el adjetivo "mortal" la caracteriza. La "secuencia", como una serie de sucesos, tiene la capacidad de "arrancar", de sentido "iniciar", "empezar".

Ej. 10. El hecho de que no avisaran, (...) la magnitud de la tragedia y la mecánica del atentado hicieron pensar a los servicios antiterroristas de que los ataques no era obra de ETA (EP, 12.03.2004).

Ej. 11. Los bomberos fueron los primeros en afrontar la tragedia (EP, 12.03.2004).

Ej. 12. Los usuarios de los cercanías del Corredor del Henares volvieron ayer a los trenes de la tragedia (EP, 17.03.2004).

Ej. 13. 1.300 héroes anónimos para una tragedia (EP, 13.03.2004).

Ej. 14. Se inician las labores de identificación de las víctimas y el desfile trágico de familiares por los pabellones de Ifema (EP, 25.03.2004).

Ej. 15. La secuencia mortal arrancó a las 7.40 en la estación de Atocha (...) (EP, 12.03.2004).

\section{Los atentados como un desastre natural}

Hemos seleccionado tres ejemplos ilustrativos que reflejan el encuadre "El atentado es un desastre", dos de asemejan los efectos de las explosiones de los trenes a fenómenos marítimos o acuáticos. Otra metáfora interpreta los acontecimientos de Madrid a través del fenómeno natural relativo a la montaña. El ejemplo 16 describe el ambiente después del ataque. Se compara la cantidad de personas con una marea, y los pasajeros que salieron de la estación se asemejan con el movimiento del agua marina. El ejemplo 17 se sitúa en el titular del artículo. El atentado se asemeja con el naufragio, el tren explotado se compara con la nave hundida en el mar junto con los pasajeros (las víctimas). Los restos del naufragio son los objetos personales de los pasajeros del tren atacado que todavía quedan en la estación. Por último, el ejemplo 18 compara la cantidad de los heridos que llegaban al Hospital 12 de Octubre después de las explosiones con una avalancha, la gran masa de nieve que se desprende de forma violenta y se derrumba por la vertiente de una montaña. El sustantivo “avalancha” es el foco de la metáfora.

Ej. 16. Sólo una marea humana corría mirando hacia atrás por las calles adyacentes a la estación de Atocha (EP, 12.03.2004).

Ej. 17. Restos de un naufragio en la estación atacada (EP, 13.03.2004).

Ej. 18. Todos los hospitales públicos suspendieron las intervenciones quirúrgicas programadas para dejar libres los quirófanos ante la avalancha de heridos (EP, 12.03.2004). 
El infierno y la pesadilla

Los textos analizados presentan una imagen de los atentados como un infierno y una pesadilla. Casi todas las metáforas que remiten a la violencia, al carácter cruel del atentado, las expresiones contienen los sustantivos "caos", "pesadilla", "horror", "terror". Una de las metáforas recogidas remite a una asociación casi religiosa y subraya el carácter emocional de los atentados. En el ejemplo 19 el sustantivo "infierno" presenta los "resultados" de las explosiones de los trenes. El lugar físico de los ataques se asemeja con el espacio imaginario del infierno, el carácter de los atentados trasmite el adjetivo "terrorista".

Ej. 19. Infierno terrorista en Madrid: 192 muertos y 1.400 heridos (EP, 12.03.2004).

Dos metáforas similares describen la situación en los lugares de los atentados. El ejemplo 20 es una metáfora compleja, cuyo foco es la palabra "infierno". A la explosión descrita por el adjetivo "tremenda", un fenómeno físico le atribuye la capacidad de cambiar, empeorar la realidad, en este caso, "convertir" un barrio en un "infierno". La metáfora transmite la imagen de la destrucción causada por las explosiones y remite al sustantivo "infierno" en el mismo sentido que el ejemplo 19. En el ejemplo 21 se emplea el sustantivo "pandemónium" en sentido metafórico para describir la situación en el barrio cerca del apeadero de Pozo del Tío Raimundo. Por una parte, se transmite la imagen de la zona atacada con la confusión de los heridos, las ambulancias que llegan para auxiliarlos. Este sentido refuerza el comple- mento "de ambulancias". Por otra parte, el contexto de la metáfora, el acontecimiento que describe generan la asociación del lugar del atentado con la capital del infierno. El ejemplo 22 compara el proceso de la búsqueda de las víctimas por sus familiares y la identificación de los fallecidos con un "tormento" para los familiares, el pabellón ocho, que remite al sitio de la identificación, funciona como el lugar físico de materialización de la metáfora.

Ej. 20. (...) a las 7.39 escuchó la tremenda explosión que convirtió el barrio en un infierno (EP, 12.03.2004).

Ej. 21. La zona se convirtió en un pandemónium de ambulancias a la carrera (...) (EP, 12.03.2004).

Ej. 22. El tormento del pabellón ocho (EP, 12.03.2004).

Tres metáforas ilustrativas presentan el "terror" y sus atributos como un acto de violencia y a los sujetos capaces de causarla. Según indica el ejemplo 23, las explosiones tienen la capacidad de "sembrar" el terror, que, a su vez, se asemeja al poder de generación de una semilla. El mismo esquema funciona en el ejemplo 24, pero en este caso "siembran el terror" las bombas, los objetos físicos. Ambos ejemplos resumen de forma lacónica, emocional y evidente lo ocurrido.

Ej. 23. Diez explosiones en cuatro trenes de cercanías siembran el terror (EP, 12.03.2004).

Ej. 24. Tres bombas siembran el terror y causan al menos 34 muertos en un tren de cercanías (EP, 12.03.2004).

Las metáforas 25-28 muestran el uso del sustantivo "caos" en sentido 
metafórico para describir las situaciones en los lugares de las explosiones inmediatamente después de los ataques. El ejemplo 25 presenta el ambiente en la estación. La metáfora se sitúa en el segundo párrafo del texto y remite a la confusión que provocó la explosión, que se concreta en el sustantivo "caos". El ejemplo 26 muestra el cambio de ambiente cuando se produjeron dos explosiones más. La situación de antes se presenta como el "caos", y el después como la "pesadilla". El ejemplo 27 trata de la reacción de los pasajeros del último tren que abandonó la estación de Atocha antes de las explosiones y se basa en el relato de uno de ellos. El tren que salió de Atocha llegó a la estación de Santa Eugenia cuando ya había explotado otro tren allí. El ambiente en la estación atacada se califica como de "caos", se añade la característica, "absoluto". El ejemplo 28 califica como "caos de personas" la situación que vieron los bomberos tras llegar al sitio. El sustantivo "caos" se emplea aquí en sentido de desorden, la reacción descoordinada, el pánico. El ejemplo 29 remite a los atentados como un muerto que ha dejado su "fantasma".

Ej. 25. Cuando el convoy estaba a punto de detenerse en la estación de Atocha, el caos comenzó (EP, 12.03.2004).

Ej. 26. Lo que hasta entonces era caos se convirtió en pesadilla (EP, 12.03.2004).

Ej. 27. El caos era absoluto cuando el tren que salió de Atocha a las 7.35 llegó a Santa Eugenia (EP, 12.03.2004).

Ej. 28. Lo que se encontraron allí fue un caos de personas corriendo despavoridas entre las vías, heridos y muertos entre los dos vagones destrozados del tren (EP, 12.03.2004).

Ej. 29. El fantasma del 11-M está presente en el Servicio de Documentación para Extranjeros, en el número 90 de la madrileña calle del general Pardiñaz (EP, 19.03.2004).

El último grupo de metáforas remite a los atentados como símbolo del horror, este sustantivo funciona como el foco de la metáfora en dos de los tres casos. El ejemplo 30 describe la reacción de los vecinos de las zonas en que se produjeron los atentados. La situación que vieron tras salir de sus casas se califica como "horror", para reforzar la imagen se emplea el adjetivo "verdadero". La imposibilidad de ignorar en aquel momento la magnitud del atentado y la cantidad de heridos se transmite por el verbo "tapar", como algo que no se puede ocultar. Y de hecho, que nadie "intente" ocultar. El ejemplo 31 califica la cantidad de heridos y la intensidad con la que tenía que trabajar el personal médico durante las horas posteriores a los atentados. En el ejemplo 32, el atentado, la crueldad y la muerte de muchas personas se califican de "horror". Se afirma que varias personas llegaron allí para visitar el lugar del ataque y rendir su homenaje a las víctimas. Se asemeja con la "procesión", ya que se dirigen al lugar de los atentados, van "hacia el horror".

Ej. 30. Nadie intentaba tapar el verdadero horror (EP, 12.03.2004).

Ej. 31. El horror en cinco horas (EP, 12.03.2004). 
Ej. 32. En procesión hacia el horror (EP, 13.03.2004).

\section{La muerte llega en tren}

Una de las ideas destacadas en los textos informativos dedicados a los atentados de Madrid remite a los conceptos de matanza y muerte. Los ejemplos ilustrativos del uso de las metáforas que transmiten la imagen de la muerte se pueden diferenciar entre las que remiten al atentado como un acto de matar, los sujetos y los instrumentos de esta acción y las que se refieren a la muerte y la cantidad de víctimas mortales que causaron las explosiones. Todos los ejemplos apelan a la esfera semántica "Muerte".

El primer grupo contiene los sustantivos "matanza", "masacre" y "asesinos". En tres de los cuatro casos estos términos funcionan como un foco semántico de la frase. En el ejemplo 33 se emplea la expresión "matanza internacional" para indicar que las víctimas de los atentados fueron de diversos países. En el ejemplo 34 encontramos la expresión "cuatro atentados", y a ellos les atribuye la capacidad de "provocar una matanza", de matar a los seres vivos. Aunque se trata de una metáfora cotidiana, es un caso interesante que muestra la capacidad de dicha figura de transmitir la idea en una forma visual al tiempo que deja en un segundo plano la autoría, es decir, la localización en responsabilidad de los mismos, sobre la que el gobierno mantenía la controversia. En el ejemplo 35 se emplea el sustantivo "masacre" para referirse a los atentados, pero lo que convierte este término en la metáfora es el atributo "de trenes", que conecta la masacre con el lugar y la especifica de los ataques producidos. La expresión "trenes asesinos" (ejemplo 36) presenta estos vehículos como seres con capacidad criminal. "Asesinos" es el foco semántico de la metáfora.

Ej. 33. Esta ha sido una matanza internacional aunque los trenes fueran de cercanías (EP, 13.03.2004).

Ej. 34. Cuatro atentados simultáneos causan una matanza en trenes de Madrid (EP, 12.03.2004).

Ej. 35. La masacre de los trenes se convirtió en el atentado más sangriento en la historia de España y uno de los mayores de Europa (EP, 12.03.2004).

Ej. 36. Los vecinos donde estalló uno de los trenes asesinos lucharon durante años por el ferrocarril que les unía a Madrid (EP, 14.03.2004).

Entre metáforas del segundo grupo hay dos que muestran el uso del término "reguero". En el primer caso (ejemplo 37) se usa acompañado de la segunda parte de la expresión metafórica "de muerte". Las diez explosiones producidas dejaron una señal continuada de muerte, ya que una gran cantidad de personas perdieron su vida. De ahí, este reguero se construyó por la muerte. La segunda metáfora (ejemplo 38) se refiere a la cronología de las explosiones. Tras dejar un reguero en un sitio, las explosiones como instrumentos de muerte, continuaron su acción en otra estación - "el reguero mortal continuó". Aquí se emplea para caracterizar el sustantivo "reguero" el adjetivo "mortal" y se transmite la capacidad de 
difusión de la muerte, que se concreta en el verbo "continuar" en pasado.

Ej. 37. Diez de los artefactos se exploraron (...) dejando un reguero de muerte en la línea ferroviaria (EP, 12.03.2004).

Ej. 38. El reguero mortal continuó por la estación de Pozo Entrevías (...) (EP, 12.03.2004).

El ejemplo 39 es una metáfora muy ilustrativa, que presenta la cronología de los ataques dos días después. El foco de la metáfora es el sustantivo "tren", pero la intensidad semántica recae en el complemento "de muerte". Pensamos que esta expresión tiene en su base dos asociaciones. La matanza de personas inocentes se presenta como una tragedia. Además, el tren como un medio de transporte se presenta aquí como un medio usado para la muerte. La segunda asociación remite a la muerte que llegó en el tren. El ejemplo 40 presenta una expresión metafórica compleja que identifica el movimiento del tren con pasajeros dentro con el movimiento de la vida, que se acaba con la muerte. La muerte es el punto de destino. Los pasajeros que viajan son un "puñado", un número indeterminado. Este sustantivo funciona como foco de la metáfora.

Ej. 39. El primer y segundo tren de la muerte compartieron andén en la estación de Alcalá (EP, 13.03.2004).

Ej. 40. De ella salieron un puñado de vecino rumbo a la muerte de la mañana del 11-M (EP, 14.03.2004).

\section{Madrid es víctima del ataque}

Tras hablar de los textos referidos al 11 de septiembre y los discursos políticos so- bre los ataques terroristas, Lakoff ha señalado el uso frecuente de las metáforas conceptuales del tipo "Una nación es un hombre" (Lakoff, 2007, pp. 60-61). La personificación la menciona también Teruel nombrando los recursos de expresividad del lenguaje periodístico (1997, pp. 286-287). Una de las variedades de esta metáfora se usa en los textos de El País para hablar sobre los ataques de Madrid y remite al encuadre que presenta la ciudad donde ocurrieron los acontecimientos como una persona, víctima de los terroristas. Hemos seleccionado un ejemplo ilustrativo del uso de la metáfora "Madrid es una persona". El ejemplo 41 se refiere a los sentimientos un tiempo después de los ataques. Madrid se presenta aquí como una ciudad capaz de experimentar los estados de ánimo de sus habitantes tras lo ocurrido.

Ej. 41. Madrid es una ciudad entristecida desde la tarde. La noche cae en silencio (EP, 25.03.2004).

\subsection{Encuadres de consecuencias y re- acciones}

La ola de la solidaridad

Las metáforas que remiten a la reacción emocional de los ciudadanos y los familiares de las víctimas se pueden dividir entre las imágenes metafóricas de la solidaridad, la compasión, y las personificaciones de los sentimientos, el dolor causado por el ataque. El primer grupo se presenta con una metáfora que se refiere a la solidaridad que expresa la gente con las víctimas del ataque y otras figuras de lenguaje. El ejemplo 42 incluye una metáfora compleja. A los atentados les atribuye la capacidad humana de 
"desencadenar" algo, para describir lo que desencadena se usa otra metáfora simple "una ola de solidaridad". La reacción de los ciudadanos se interpreta como una ola, un movimiento de agua, provocado por algunos fenómenos acuáticos, en este caso metafóricamente provocado por los atentados.

Ej. 42. Los atentados de ayer desencadenaron una ola de solidaridad por toda la capital que alcanzó desde los ciudadanos que residen cerca del lugar de los atentados (...) (EP, 12.03.2004).

Entre las metáforas que reflejan el estado emocional de los parientes de las víctimas y los mismos heridos en las explosiones se pueden destacar los ejemplos del uso del término "dolor". En algunos casos el "dolor" se presenta como un humano, un ser vivo, en otros se personifican los lugares físicos u objetos relacionados con los ataques. El ejemplo 43 describe los estados emocionales de las personas participantes en el acto como "atrapados entre el dolor y la impotencia". Se oponen el sentimiento, el dolor, y el estado físico, la impotencia. El primer sustantivo remite a la reacción por la muerte injusta de muchas personas, mientras que el segundo refleja la incapacidad de hacer algo frente a ataques de este estilo. Además, el sustantivo "lluvia" se refiere a las lágrimas como muestras del dolor. La metáfora 44 presenta el "dolor" como sentimiento o sensación física que afecta a la zona entre dos estaciones. De esta forma, se asemeja la zona con el organismo humano, el hombre que siente el dolor en alguna parte: los vecinos de la zona se presentan como una persona "colectiva" que siente dolor. El ejemplo 45 muestra el "dolor" como un sentimiento dominante en la percepción de los atentados casi dos semanas después. Se presenta el "dolor" como un hombre o un animal capaz de "recorrer" la ciudad.

Ej. 43. $Y$ a muchos, atrapados entre el dolor y la impotencia, no era lluvia lo que le corría por las mejillas (EP, 13.03.2004).

Ej. 44. Dolor entre Santa Eugenia y la Puerta de Atocha (EP, 14.03.2004).

Ej. 45. Hay un dolor que recorre toda la capital, una necesidad de guardarse y olvidar (EP, 25.03.2004).

\section{Encuadres y metáforas de The Guardian}

\subsection{Encuadres descriptivos}

\section{Masacre en Madrid}

En los textos informativos del diario inglés se pone de manifiesto la idea de la matanza y la muerte como línea principal en la cobertura de los atentados. El ejemplo 46 presenta los acontecimientos de Madrid a través del sustantivo "massacre". El ejemplo 47 presenta los efectos de la explosión de los trenes en un contraste expresivo con el momento del año en que ocurren. La primavera representa una explosión de vida, en cambio, la mañana de las explosiones de trenes en Madrid viene definida por los términos "bloodshed and carnage". Ambas metáforas transmiten la idea de la crueldad de las explosiones, y al mismo tiempo, remiten a la gran cantidad de víctimas. El ejemplo 48 interpreta el estado emocional de los familiares que buscan a sus parientes esperando encontrar noticias sobre 
ellos a través del sustantivo "agony", el estado de un organismo vivo a punto de morir. Las familias se presentan como hombres que mueren por no recibir noticias de los suyos.

Ej. 46. Massacre in Madrid (TG, 12.03.2004).

Ej. 47. One early spring morning of bloodshed and carnage appeared to have given the armed Basque separatist group ETA, officially blamed for the Madrid attacks (TG, 12.03.2004).

Ej. 48. He kept calling her but there was no answer: Agony of families (TG, 13.03.2004).

El ejemplo 49 es una expresión frecuentemente usada en la lengua inglesa, el sonido de la campana ("toll") simboliza aquí el llamamiento de la muerte. El sustantivo "toll" junto con "death" forman el foco de la expresión, mientras los verbos "continue to rise" transmiten la continuidad de la acción, la muerte sigue llamando a nuevas víctimas. El ejemplo 50 presenta la ciudad (en este caso, los suburbios) como una persona que sufrió por las explosiones. La cantidad de personas muertas procedentes de esta ciudad se asocia con el precio ("cost") que ha pagado.

Ej. 49. The death toll continued to rise during the day as some of the injured died (TG, 13.03.2004).

Ej. 50. Suburb through which all bombed trains passed counts the cost (TG, 13.03.2004).

La expresión 51 remite a la historia de las víctimas y trata de la muerte de un padre y su hijo en el mismo tren. El sustantivo "door" se emplea al referirse a la muerte de las personas. La puerta ("door") sirve para salir de un sitio, y en este caso tiene el valor simbólico de "salir" de la vida. Se añade al foco de la expresión el adjetivo "tragic" con el intensificador "the most", que caracterizan la muerte coincidida de dos personas de la familia.

Ej. 51. But the most tragic door of all contained the names of a father and son, Francisco and Jorge Fernandez, aged 52 and 22 (TG, 13.03.2004).

\subsection{Encuadres de consecuencias y re- acciones}

El apoyo y la lucha contra el terrorismo

Uno de los encuadres que remiten a las consecuencias y la reacción a los ataques producidos presenta la idea de la necesidad de luchar contra el terrorismo a nivel mundial y la solidaridad con el país agredido. Dos de las metáforas seleccionadas inciden en la reacción mundial a los acontecimientos del 11 de marzo. La idea que transmiten indica el apoyo internacional a Europa, ya que las explosiones de trenes en Madrid se califican como la agresión contra el continente viejo. El ejemplo 52 transmite la reacción de Gran Bretaña y, en particular, la del primer ministro Tony Blair. Se señala la necesidad de luchar contra los terroristas, "to continue the fight". El terrorismo se presenta como un enemigo a batir en el conflicto. El ejemplo 53 muestra la reacción de los líderes mundiales fuera de Europa, de Putin y Bush. En ambos casos los presidentes son representantes de sus países, los nombres propios funcionan de forma metonímica. En este ejemplo se puede observar 
también un caso de personificación del continente. Los atentados de Madrid se presentan como "Europe's outrage" ("indignación de Europa"), esta parte de la frase lleva la intensidad semántica. Se presentan los ataques como una acción que causa daños graves a la persona. A su vez, Europa se asocia con una persona indignada. Bush y Putin se figuran como los líderes capaces de guiar esta indignación.

Ej. 52. Britain: Blair pledges to continue fight against terrorism (TG, 12.03.2004).

Ej. 53. Reaction: Bush and Putin lead Europe's outrage (TG, 12.03.2004).

Los resultados de las elecciones: una reacción de los ciudadanos

Algunas metáforas interpretan los resultados de las elecciones del 14 de marzo como la reacción de los ciudadanos españoles a los ataques. El ejemplo 54 explica que los resultados de las elecciones aparecieron bajo la influencia de los atentados, "the grim reminders", los recuerdos sombríos. En el ejemplo 55 la expresión "power balance" se emplea para caracterizar el equilibrio entre varios grupos políticos en su lucha por el poder y la confianza de los ciudadanos. Este equilibrio estalló en mil pedazos tras la política informativa del Gobierno.

Ej. 54. But as voters filed in, it was clear that the grim reminders of Thursday's bombing would cause an angry electorate to punish the People's party (PP) in spectacular fashion (TG, 15.03.2004).

Ej. 55. Power balance blown apart: World briefing (TG, 16.03.2004).
Las lecciones del 11 de marzo

El último de los encuadres de la categoría de consecuencias responde a la idea de que los atentados de Madrid son capaces de enseñar (ejemplo 56). Las explosiones de Madrid poseen aquí la capacidad de enseñar, dar lecciones. La capacidad humana atribuida al atentado se realiza en la forma del verbo "provide".

Ej. 56. March 11 in Madrid has provided other lessons, too (TG, 16.03.2004).

\section{Encuadres y metáforas de Izvestia 6.1. Encuadres descriptivos El 11 de septiembre europeo}

La metáfora que asocia los ataques producidos con los del 11 de septiembre (ejemplo 57) transmite la idea general del tratamiento informativo de los atentados de Madrid en Izvestia. Por una analogía histórica, estos ataques se comparan con los del 11 de septiembre por su crueldad y posible influencia en la política. Además, se señala el significado del acontecimiento para toda Europa, ya que es el "11 de septiembre" europeo, no español.

Ej. 57. У Европы теперь своё 11 сентября (Europa ya tiene su propio 11 de septiembre) (IZV, 12.03.2004).

\section{La tragedia de Madrid}

La imagen de los atentados como una tragedia se realiza por dos metáforas. El ejemplo 58 califica los atentados como tragedia, el adjetivo "madrileña" incide en el lugar. El ejemplo 59 posee la cadena metafórica más complicada. Por una parte, se puede observar un 
caso de personificación. España se asocia con una persona, que esta enterrando a sus parientes. Por la presencia abundante de ejemplos que remiten al país y la ciudad en calidad de personas hemos decidido centrar el análisis en la segunda parte de la expresión. Por otra parte, las explosiones se califican indirectamente como causa de la tragedia, ya que las víctimas son "víctimas de la tragedia”. Esta línea remite también a la percepción general del género de la tragedia que frecuentemente supone la muerte del héroe o héroes principales. Se refiere al concepto de la tragedia en sentido metafórico cotidiano, detectado también en los textos españoles.

Ej. 58. Единственная тема экстренных телевыпусков - мадридская трагедия (El único tema de las noticias televisivas extra es la tragedia madrileña) (IZV, 12.03.2004).

Ej. 59. В выходные Испания хоронила жертв трагедии (El fin de semana España enterraba a las víctimas de la tragedia”) (IZV, 14.03.2004).

\section{El Gobierno engaña a la población}

Aunque los textos que remiten a la responsabilidad de $\mathrm{Al}$ Qaeda y las redes del terrorismo internacional no contienen ejemplos del uso de la metáfora como canal de transmisión de este encuadre, contienen, por el contrario, ejemplos que se refieren a la culpa del Gobierno por ocultar la información sobre los responsables en el atentado. El ejemplo 60 compara los intentos del Gobierno por mantener la versión oficial sobre la culpa de ETA con la guerra, la batalla perdida, ya que, al final, el ministro de Interior "capituló” («капитулировал»). El ejemplo 61 presenta al Gobierno como un hombre que se aferra a la versión de la autoría de ETA. Se asemeja a un objeto que "se toma con fuerza”, tanta que se convierte en algo enfermizo intensificar la metáfora se añade el adjetivo "febrilmente", lo que señala la asociación adicional con la enfermedad.

Ej. 60. Лишь в ночь на воскресенье министр внутренних дел капитулировал. Дальнейшее молчание было уже просто неприличным (Sólo el domingo por la el ministro de asuntos interiores capituló. Seguir callando ya fue insostenible) (IZV, 14.03.2004).

Ej. 61. Почему испанское правительство так медлило? Почему ихорадочно цеплялось за версию, что за терактами стоят баскские сепаратисты из группировки ЭТА (...)? (¿Por qué el Gobierno español tardó tanto? ¿’Por qué tan febrilmente se tomó con fuerza la versión de que los separatistas vascos de ETA estaban detrás de los atentados?) (IZV, 14.03.2004).

\subsection{Encuadres de consecuencias y re- acciones}

El Gobierno perdió por engañar a la población

Este encuadre transmite la idea de que los resultados de las elecciones fueron generados por la política informativa del Gobierno español, que durante tres días habló de la responsabilidad de ETA, aunque las pruebas indicaban a $\mathrm{Al}$ Qaeda. El ejemplo 62 presenta los resultados de las elecciones en relación 
con los atentados. Los ciudadanos, como se indica en el texto, "preguntaban" sobre la verdad de los responsables de los ataques, pero el Gobierno "no les escuchó" y no ha respondido de forma adecuada. El hecho de que el partido gobernante perdiera las elecciones se explica por dos causas: la guerra en Iraq a la que nunca apoyó la población española y la mentira hacia los responsables de los ataques en Madrid. A los ciudadanos, como indica el texto, "no les gusta que les mientan" («они не любят, когда им лгут»). Se asocia al Gobierno con una persona que no escuchó a otra (el pueblo) y por eso "pagó", perdió las elecciones.

Ej. 62. Правительство Аснара их не слышало. И теперь за это поплати^ось (El Gobierno de Aznar no les escuchó. Y ahora pagó por eso) (IZV, 16.03.2004).

\section{Conclusiones}

Los resultados obtenidos verifican en la práctica la posibilidad de vincular dos aproximaciones, la periodística y la lingüística, en un enfoque combinado. La teoría del framing, plasmada al estudio de textos noticiosos permite destacar los encuadres como las ideas dominantes y las estrategias discursivas que emplea un periódico para transmitir una interpretación de un objeto informativo.

Como muestra el análisis, los textos informativos transmiten un punto de vista peculiar sobre aquellos acontecimientos que narran, en todos ellos se demuestra la presencia del periodista, a través de un claro elemento calificativo, de una mirada particular sobre los su- cesos que exponen los textos. En este aspecto, los textos noticiosos presentan la realidad desde unos determinados encuadres o frames, lo que posibilita acentuar unos aspectos mientras se dejan otros en segundo plano.

A su vez, la metáfora como una herramienta cognitiva, una figura capaz de influir en la construcción social de la realidad, juega uno de los papeles primordiales a la hora de transmitir el encuadre. Así se evidencia en las metáforas utilizadas por los tres periódicos a la hora de informar sobre el ataque terrorista del 11-M.

En comparación con otros periódicos El País presenta una amplia diversidad de encuadres descriptivos, metáforas y esferas semánticas a través de las cuales se realizan. Este hecho pensamos, se explica por la proximidad del evento, ya que tanto los lectores como los propios periodistas sufren una percepción más emocional e intentan atrapar más el acontecimiento, que sus consecuencias y reacciones.

Las metáforas y los encuadres que comparten los diarios presentan el atentado como un espectáculo. Las diferencias que se notan remiten a las referencias de diversos atributos y representaciones teatrales: el periódico español utiliza una gran variedad de metáforas con sustantivos "drama", "tragedia", "escenario". El diario ruso se limitó al uso del término "tragedia”.

Otra imagen que reparten los periódicos en los tres casos analizados es la presentación de los ataques terroristas como una acción inhumana, a través de encuadres descriptivos que se traducen 
en metáforas de la esfera "Monstruos e imaginario". A la hora de describir el ambiente en los lugares de los atentados los tres periódicos a menudo remiten a los conceptos "caos", "pesadilla", "horror" o "pánico".

Adicionalmente, los periódicos comparten las metáforas referidas a la esfera "Muerte". Se puede observar, sin embargo, las diferencias entre la selección de términos en tres casos. Por ejemplo, son típicas para el periódico español las metáforas que contienen sustantivos "muerte", "asesino", mientras el diario inglés emplea "bloodshed" o "agony".

El periódico español alude a las esferas "Mar" y "Geo". Un ataque terrorista se asemeja a un desastre o a un fenóme- no incontrolable y trágico por sus consecuencias, sea de carácter marítimo (naufragio, marea) o montañoso (avalancha), elementos que resultan familiares para los lectores por su proximidad.

Por último, entre las consecuencias de los ataques que notan The Guardian e Izvestia hay unos que remiten a los resultados de las elecciones de 14 de marzo como una de las consecuencias de los atentados y emplean metáforas críticas al referirse a esta idea. Ello permite afirmar el carácter más analítico de los encuadres de consecuencias y reacciones presentados por estos diarios en los textos noticiosos en comparación con $E l$ País.

\section{Bibliografía}

Cappella, J. N. \& Jamieson, K. H. (1996). News Frames, Political Cynicism, and Media Cynicism. Annals of the American Academy of Political and Social Science, (546), 71-84.

Cole, P. \& Harcup, T. (2010). Newspaper Journalism. London: SAGE Publications.

El País. (20 de febrero de 2005). El País bate su récord de difusión y supera un 52\% al segundo. El País. Recuperado de: https://elpais.com/diario/2005/02/20/ sociedad/1108854007_850215.html

Entman, R. M. (1991). Framing U.S. coverage of international news: Contrasts in narratives of the KAL and iran air incidents. Journal of Communication, 41(4), 6-27.

Entman, R. M. (1993). Framing: Toward clarificaction of a fractored paradigm. Journal of Communication, 43(4), 51-58.

Entman, R. M. (2003). Cascading activation: Contesting the white Houses's frame after 9/11. Political Communicaction, 20(4), 415-432. Recuperado de: https://ru.scribd.com/document/178662074/ Entman-cascading-Activation-Contesting-the-White-House-s-Frame-After-9-111

Gamson, W. A. \& Lash, K. E. (1983). The Political Culture of Social Welfare Policy. In Spiro, S. E. y Yuchtman-Yaar, E. (Ed.), Evaluating the Welfare State: social and political perspectives (pp. 397-415). New York: Academic Press.

Gamson, W.A. \& Modigliani, A. (1989). Media discourse and public opinion on nuclear power. American Journal of Sociology, 95(1), 1-37. Recuperado de: http://www.jstor.org/ stable/2780405

Gómez Mompart, J. L. \& Marín Otto, E. (eds.) (1999). Historia del periodismo universal. Madrid: Síntesis. 
Lakoff, G. \& Johnson, M. (1995). Metáforas de la vida cotidiana. Madrid: Cátedra.

Lakoff, G. (2007). No pienses en un elefante. Lenguaje y debate político. Madrid: Editorial Complutense.

Ovsepján R.P. (2005). Исто́рия нове́йшей оте́чественной журнали́стики: февра́ль 1917 нача́ло ХХІ в. [Historia del periodismo nacional contemporáneo: febrero de 1917 - principios del siglo XXI]. Moscú: Naúka.

Pan, Z. \& Kosicki, G. M. (1993). Framing analysis: Approach to news discourse. Political Communication, (10), 55-75.

Portilla, R. (2012). Propuesta metodológica para el análisis de los encuadres periodísticos en la cobertura de narcotráfico en México. Revista Iberoamericana De Comunicación, (22), 43-72. Recuperado de: https://documentslide.org/ portilla-2012-propuesta-metodologica-para-el-estudio-de-los-encuadres-periodisticos

Reese, S. D. \& Lewis, C. S. (2009). Framing the war on terror. the internalization of police in the US press. Journalism, 10(6), 777-797. Doi: https://doi.org/10.1177/1464884909344480

Reyna García, V. H. (2017). Estudios culturales y laborales del periodismo: una revisión bibliográfica. Balajú. Revista de cultura y comunicación, 6, pp. 3-21. Recuperado de: http://revistas.uv.mx/index.php/balaju/article/view/2874/5042

Sádaba, T. (2001). Origen, aplicación y límites de "teoría de encuadre" (framing) en comunicación. Comunicación y Sociedad, 14(2), 143-175. Recuperado de: https://www.unav.es/fcom/ communication-society/es/resumen.php?art_id=335

Sádaba, T. (2008). Framing: El encuadre de las noticias. el binomio terrorismo-medios. Buenos Aires: La Crujía.

Scheufele, D. A. (1999). Framing theory of media effects. Journal of Communication, Winter, 103-122.

Schulze, I. (2004). Capítulo 5. La prensa escrita en los principales países occidentales. In Barrera, C. (Coord.), Historia del periodismo universal (pp. 169-228). Barcelona: Ariel.

Semetko, H. A. \& Valkenburg, P. M. (2000). Framing European Politics: Content Analysis of Press and Television News. Journal of Communication. Spring, pp. 93-109. Doi: 10.1111/j.1460-2466.2000.tb02843.x

Seoane, M. C. \& Saiz, M. D. (2007). Cuatro siglos de periodismo en España: de los avisos a los periódicos digitales. Madrid: Alianza.

Seoane, M. C. \& Sueiro, S. (2004). Una historia de El País y del Grupo Prisa. Madrid: Plaza y Janés. Servicio Nacional de Imprenta (2 de diciembre de 2004). Тираж - рекорд года 2004 [La tirada - el récord del año 2004]. Servicio Nacional de Imprenta. Recuperado de: http://pressaudit.ru/tirazh-rekord-goda-2004/

Teruel, E. (1997). Retòrica, informació i metáfora: Anàlisi aplicada als mitjans de comunicació de massa. Barcelona: Universitat Autònoma de Barcelona.

Van Gorp, B. (2007). The constructionist approach to framing: Bringing culture back in. Journal of Communication, 57(1), 60-78. Doi: 10.1111/j.0021-9916.2007.00329.x

Vólkova T. А. (2009). A. I. Аджубе́й - реда́ктор и публициист [A.I. Adzhubéj-el editor y el periodista] (Tesis doctoral). Universidad Estatal de Moscú “M.V. Lomonosov”, Moscú, Rusia. Recuperado de: https://dlib.rsl.ru/viewer/01003462370\# ?page=3 